\title{
“PODE CONTAR COMIGO E COM O GRUPO PRO QUE PRECISAR": AUTORIA, ÉTICA E PARTICIPAÇÃO NA PESQUISA COM JOVENS INTERNAUTAS
}

\author{
Dilton Ribeiro Couto Junior ${ }^{1}$ \\ Maria Luiza Magalhães Bastos Oswald ${ }^{2}$ \\ Helenice Mirabelli Cassino Ferreira ${ }^{3}$ \\ Felipe da Silva Ponte de Carvalho
}

Resumo: As pesquisas que investigam no contexto das redes sociais digitais vêm se tornando mais comuns nas ciências humanas. Privilegiamos uma relação de parceria com os sujeitos, reconhecendo que a interação com eles é imprescindível na formulação dos caminhos metodológicos do estudo. Esses percursos de pesquisa na internet são o foco de discussão deste artigo, que busca compreender os processos de participação, ética e autoria implicados numa investigação fruto de pesquisa de doutorado recentemente concluída. Para isso, partimos da abordagem histórico-cultural, centralizando nossos esforços teórico-metodológicos nas contribuições de dialogismo e alteridade de Mikhail Bakhtin e de seus interlocutores, que privilegiam a participação do outro na escolha dos percursos metodológicos e na produção do conhecimento.

Palavras-chave: Dialogismo. Ética. Pesquisa.

${ }^{1}$ Pós-doutorando (bolsista PNPD/CAPES) e professor no Programa de Pós-Graduação em Educação, Cultura e Comunicação em Periferias Urbanas (PPGECC) da Universidade do Estado do Rio de Janeiro/Baixada Fluminense (UERJ/FEBF). E-mail: junnior_2003@yahoo.com.br

${ }^{2}$ Professora Associada da Faculdade de Educação e do Programa de Pós-Graduação em Educação da Universidade do Estado do Rio de Janeiro (ProPEd/UERJ). Líder do Grupo de Pesquisa Infância, Juventude, Educação e Cultura (IJEC). E-mail: moswalduerj@yahoo.com.br

${ }^{3}$ Professora Adjunta da Faculdade de Educação da Universidade do Estado do Rio de Janeiro (UERJ). Membro do Grupo de Pesquisa Infância, Juventude, Educação e Cultura (IJEC). E-mail: tucassino@gmail.com

${ }^{4}$ Doutorando no Programa de Pós-Graduação em Educação da Universidade do Estado do Rio de Janeiro (ProPEd/UERJ). Bolsista de Doutorado-Sanduíche FAPERJ na Universidad Complutense de Madrid. E-mail: felipesilvaponte@gmail.com 


\title{
"YOU CAN COUNT ON ME AND WITH THE GROUP WITH ANYTHING YOU NEED": AUTHORSHIP, ETHICS AND PARTICIPATION IN A RESEARCH WITH YOUNG INTERNET USERS
}

\begin{abstract}
The researches that investigate in the context of digital social networking have become more common in human sciences. We value a relation with the subjects, recognizing that the interaction with them is essential to formulate the methodological research paths. These Internet research paths are the main focus of discussion of this article, which seeks to understand the processes of participation, ethics and authorship involved in an recently concluded doctoral investigation. To do so, we part from the historical-cultural research approach, centralizing our theoretical-methodological efforts on the contributions of dialogism and otherness of Mikhail Bakhtin and his interlocutors, which privilege the participation of the other in the choice of the methodological paths and in the production of knowledge.
\end{abstract}

Keywords: Dialogism. Ethic. Research.

\section{"PUEDES CONTAR CONMIGO Y CON EL GRUPO PARA LO QUE NECESITES": AUTORÍA, ÉTICA Y PARTICIPACIÓN EN LA INVESTIGACIÓN CON JÓVENES INTERNAUTAS}

Resumen: Las investigaciones que se realizan en el contexto de las redes sociales digitales se han hecho más comunes en las ciencias humanas. Privilegiamos una relación de cooperación con los sujetos, reconociendo que la interacción con ellos es imprescindible en la formulación de los caminos metodológicos de estudio. Tales recorridos de investigación en Internet son el enfoque de la discusión de este artículo, que busca comprender los procesos de participación, ética y autoría implicados en una investigación fruto de un estudio de doctorado recién concluido. Para ello, partimos del abordaje histórico-cultural, centralizando nuestros esfuerzos teórico-metodológicos en las contribuciones del dialogismo y alteridad de Mijail Bajtin y de sus interlocutores, que privilegian la participación del otro en la elección de los recorridos metodológicos y en la producción del conocimiento.

Palabras clave: Dialogismo. Ética. Investigación. 
Introdução

A pesquisa em ciências humanas, que se inspira na arquitetura bakhtiniana para pesquisar com o outro, encontra nos princípios de dialogismo e alteridade subsídios teórico-metodológicos imprescindíveis. Com Bakhtin (2011, p. 400), reconhecemos que o sujeito "não pode ser percebido e estudado como coisa porque, como sujeito e permanecendo sujeito, não pode tornar-se mudo; consequentemente, o conhecimento que se tem dele só pode ser dialógico". As palavras ditas ao outro se renovam constantemente e adquirem sentidos diversos na comunicação dialógica, cuja imprevisibilidade, irrepetibilidade e o caráter livre do diálogo entre os sujeitos tornam cada encontro com o outro um acontecimento. (JOBIM E SOUZA; ALBUQUERQUE, 2012). A pesquisa que privilegia a produção do conhecimento a partir das dimensões dialógica e alteritária reconhecem que pesquisador e pesquisados modificam-se mutuamente e colocam-se abertos para a escuta cuidadosa e atenta.

0 pesquisador não “dá a voz" para o pesquisado, pois ambos são sujeitos de linguagem e produtores de discursos (COUTO JUNIOR; FERREIRA; OSWALD, 2017). Essa postura de pesquisa torna ambos autorizados a perguntar e a responder, rompendo com a hierarquia do saber e horizontalizando a relação com o outro. Geraldi (2007, p. 42) reitera que “assumir a relação dialógica como essencial na constituição dos seres humanos não significa imaginá-la sempre harmoniosa, consensual e desprovida de conflito". É no embate das ideias divergentes que novos pontos de vista podem ser percebidos e ressignificados, não cabendo ao pesquisador determinar o "certo" e o "errado", mas ampliar os sentidos construídos com os sujeitos sobre os acontecimentos da vida.

Ramos e Schapper (2010, p. 29), referindo-se à produção e negociação dos sentidos envolvidos no contexto dialógico, mostram que "nosso enunciado é réplica de um diálogo que incorpora e se apropria do discurso de outrem. Por isso, os enunciados são sempre dependentes do já dito e só podem ser compreendidos no fluxo da cadeia de interação verbal”. Dessa forma, não há como negar que "o nosso discurso da vida prática está cheio de palavras de outros” (BAKHTIN, 2008, p. 223), com a comunicação dialógica possibilitando que palavras anteriormente ditas possam ser rememoradas, adquirindo novos sentidos e ressignificações na relação com o outro. A perspectiva dialógica e alteritária de Mikhail Bakhtin não defende que as palavras ditas vão ao 
encontro de uma mesma linha de pensamento, uma vez que as diferentes perspectivas ampliam a capacidade do outro de conhecer pontos de vista singulares e que não foram previstos a priori. Nesta ótica, "a palavra do pesquisador recusa-se a assumir a aura de neutralidade imposta pelo método e integra-se à vida, participando das relações e das experiências [...] que o encontro com o outro proporciona". (PEREIRA; SALGADO; JOBIM E SOUZA, 2009, p. 1023).

Recentemente, com a popularização dos computadores pessoais e dispositivos digitais móveis, inúmeras palavras vêm sendo enunciadas e amplamente compartilhadas nas diversas redes sociais da internet. São palavras escritas que nos revelam as histórias, gostos, ideias e os desejos dos internautas. Esses processos comunicacionais, dos quais os jovens participam na contemporaneidade, poderiam ser uma indicação que as experiências mediadas pelas tecnologias digitais em rede reconfiguram a forma como recebem e adquirem informação e conhecimento com 0 outro. A relação dos jovens com as tecnologias digitais vêm propiciando a emergência de novas sociabilidades, sendo que essas mudanças culturais reforçam a necessidade de que olhares cuidadosos sejam lançados sobre as práticas sociais juvenis na era digital. (ROSA; FERREIRA; OSWALD, 2010). Dito isso, cabe questionarmos: quais os desafios e possibilidades de pesquisar com as juventudes contemporâneas na internet? Quais formas de sociabilidade emergem com a mediação das tecnologias digitais em rede?

A rede mundial de computadores tornou possível romper com o tempo e o espaço, favorecendo que pessoas geograficamente dispersas interajam e dialoguem de praticamente qualquer lugar do mundo e a qualquer horário do dia. As práticas sociais mediadas pela cultura digital privilegiam os diversos usos das palavras escritas, indo desde pequenas mensagens de textos trocadas entre os usuários de telefones móveis à composição dos textos produzidos e postados pelos internautas em redes sociais como o Twitter e o Facebook. Vale destacar que as imagens e os vídeos também apresentam centralidade nos processos comunicacionais dos sujeitos nas redes sociais e, geralmente, são acompanhados de palavras escritas, responsáveis pela manutenção ainda maior dos laços sociais e afetivos entre os internautas. Segundo afirma Lemos (2007, p. 38), a cibercultura constitui-se não apenas pela possibilidade de produzir e consumir informação, mas de publicizá-las também 
através das práticas do compartilhamento: "É preciso emitir em rede, entrar em conexão com outros, produzir sinergias, trocar pedaços de informação, circular, distribuir". A partir das práticas sociais ciberculturais, o que os jovens publicam e compartilham na internet? 0 que, por que e para quem escrevem? Quais os desafios de fazer pesquisa na internet considerando as diversas formas com as quais é possível interagir com o outro?

Com a emergência das dinâmicas interativas do ciberespaço, diversas abordagens teórico-metodológicas constituem-se e consolidam-se na pesquisa em ciências humanas para uma melhor compreensão dos fenômenos comunicacionais nas redes sociais digitais. Hine (2008) cita algumas estratégias metodológicas frequentemente utilizadas na pesquisa na internet, como o uso de questionários online, a observação, bem como as interações do pesquisador com grupos de usuários. Além disso, a autora ressalta que diversos estudos adotam mais de um campo empírico - não se restringindo somente aos ambientes da internet -, como forma de aproximação do objeto estudado. Mesmo com a riqueza das práticas sociais do ciberespaço, é preciso considerar as palavras de Nicolaci-da-Costa (2002, p. 200), quando aponta que "há ainda um certo ceticismo em relação ao potencial transformador das novas tecnologias digitais e, principalmente, da Internet”. 0 texto da autora foi escrito há mais de uma década, e a internet permanece enfrentando resistência para legitimar-se como campo de pesquisa, mesmo quando inúmeros estudos (MACEDO, 2014; FERREIRA, 2014; PRETTO, 2014; SANTAELLA, 2013) já apontam que as tecnologias digitais em rede estão modificando as relações humanas e reconfigurando as formas de ensinar e aprender dos sujeitos.

O contexto acima apresentado é o pano de fundo deste trabalho. Fruto de pesquisa de doutorado recentemente concluída, 0 artigo analisa questões teórico-metodológicas de uma pesquisa realizada com um grupo de oitenta jovens no Facebook que não se reconhecem dentro do modelo hegemônico da heterossexualidade. 0 grupo foi criado por estudantes das ciências biológicas de uma universidade pública do Rio de Janeiro, com o objetivo de estreitar os laços sociais e afetivos e discutir questões de gênero e sexualidade a partir de imagens, vídeos e notícias online. O trabalho de campo, conduzido entre 2013 e 2015 no Facebook, contou com a participação de jovens moradores do Estado do Rio de Janeiro, com 
idades, no momento da entrada em campo, variando entre 16 e $35 \operatorname{anos}^{5}$. Um dos focos do grupo é colocar em tensão os limites da ótica heteronormativa, problematizando as relações de poder que insistem em privilegiar determinadas condutas sociais esperadas para cada um dos gêneros ${ }^{6}$. Esse grupo de jovens foi selecionado para 0 trabalho de campo em função do objetivo da tese de investigar as experiências da abjeção de jovens não-heterossexuais, ou seja, as experiências sociais que marcam negativamente determinados sujeitos, colocando-os na posição de pessoas que são recusadas com repugnância.

Nesse texto, discutimos questões teórico-metodológicas de uma pesquisa realizada na internet, focalizando as reflexões em torno de questões como autorização, ética, participação dos sujeitos na investigação, a entrada em campo e o retorno do texto escrito aos sujeitos. Para isso, partimos da abordagem histórico-cultural, centralizando nossos esforços teórico-metodológicos nas contribuições de dialogismo e alteridade de Mikhail Bakhtin e de seus interlocutores. De acordo com essa abordagem, o homem é um ser sócio-histórico, que transforma e se transforma na relação com o outro através da linguagem. (FREITAS, 2007). A compreensão verbal ocorre entre duas ou mais consciências, num contexto no qual os enunciados são produzidos socialmente, ou seja, apresentam ligação com a vida dos sujeitos. (NUNES; KRAMER, 2011). Partindo dessa abordagem ${ }^{7}$, reconhecemos as redes sociais digitais como lugares de encontro com o outro, uma vez que permitem a formação de comunidades e de novas maneiras de se socializar. Dito isso, concordamos que o Facebook é um lugar de encontro que congrega sujeitos geograficamente dispersos, pois favorece a constituição de grupalidades e sociabilidades juvenis, tornando possível que o pesquisador participe de processos comunicacionais colaborativos. Reiteramos que a infraestrutura técnica da rede mundial de computadores não é, por si só, capaz de garantir a promoção de práticas dialógicas e alteritárias. Neste sentido, privilegiamos uma relação de parceria com os

\footnotetext{
${ }^{5} \mathrm{O}$ primeiro autor desse texto conduziu o trabalho de campo no Facebook. A segunda autora do artigo é orientadora da pesquisa de doutorado em questão.

${ }^{6}$ Em outros artigos apresentamos algumas narrativas digitais sobre gênero e sexualidade que foram produzidas com os jovens no Facebook. 0 objetivo deste texto, conforme mencionado, é refletir de forma teórica e metodológica a pesquisa que adota as redes sociais digitais como campo empírico.

${ }^{7}$ Para maiores informações sobre a abordagem histórico-cultural, ver os trabalhos de Freitas (2007, 2009) e Couto Junior, Ferreira e Oswald (2017).
} 
jovens da pesquisa, reconhecendo que a relação com eles é imprescindível para que sejam refletidos e trilhados os caminhos teórico-metodológicos do estudo.

\section{“Pode Contar Comigo”: Autorização, Ética e Participação dos Sujeitos na Pesquisa}

Para que os jovens da pesquisa sejam identificados e se reconheçam no estudo, optamos pelo uso de pseudônimos escolhidos pelos próprios. Os nomes inventados por eles revelam suas histórias, desejos, ideias, possibilitando que eles escolham a forma como querem ser identificados no trabalho escrito. Essa opção teórico-metodológica diz respeito à necessidade ética encontrada para preservar as identidades dos sujeitos, impedindo que seus perfis sejam rastreados na internet por grupos que produzem e disseminam discursos de ódio sintonizados com a ótica heteronormativa. De acordo com Recuero (2013, p. 62), é preciso reiterar que “a conversação em rede é um espaço frutuoso para a emergência de discussões inflamadas, discursos agressivos e ofensivos e, mesmo, pela propagação da violência”. Vale ressaltar ainda que inúmeras páginas do próprio Facebook são destinadas a difundir discursos contra as chamadas "minorias" sociais (negros, pobres, homossexuais, dentre outros grupos). Neste sentido, também optamos por não mencionar o nome do grupo do Facebook do qual os jovens são membros, ainda mais considerando que as narrativas digitais produzidas e compartilhadas por eles são marcadas pelo preconceito e pela discriminação, revelando que muitos de seus respectivos contextos sociais são intolerantes contra as pessoas não-heterossexuais.

Em sua pesquisa envolvendo crianças de diferentes escolas com idades variadas, Kramer (2002, p. 47) também utilizou nomes fictícios. De acordo com ela, essa escolha ética ocorreu "seja porque estudavam na única escola da região e seus depoimentos traziam muitas críticas à escola e às professoras, seja porque denunciavam problemas graves vividos por elas mesmas e por suas famílias e, nesse caso, a revelação dos nomes se constituía em risco real”. Considerando que, cada vez mais, os trabalhos acadêmicos são disponibilizados na internet, cuja especificidade técnica da rede mundial permite o rápido compartilhamento e a ampla visualização por pessoas de todos os cantos do globo, é prudente a realização de uma reflexão 
cuidadosa sobre a nomeação dos sujeitos no trabalho de pesquisa em tempos de comunicação digital.

A partir da relação dialógica e alteritária estabelecida com os jovens, nos ancoramos nas discussões de Pereira (2015), para quem a ética, reconhecida como uma postura de pesquisa, é constitutiva de todas as etapas do processo investigativo. Isso significa questionar documentos como o "Termo de Consentimento Livre e Esclarecido", no qual "os sujeitos pesquisados, antes mesmo da efetiva interlocução de pesquisa, atestam concordância em participar da pesquisa e o direito de dela se retirarem em qualquer parte do processo" (PEREIRA, 2015, p. 53). Dessa forma, a ética que defendemos é construída cotidianamente com os sujeitos no Facebook, não sendo garantida pelo simples ato da assinatura de um documento pelo pesquisado. Concordamos que não existe uma única forma de pesquisar e, consequentemente, a ética pode ser pensada de diferentes maneiras no fazer científico. (PEREIRA, 2015). De forma alguma estamos sugerindo que as investigações nas ciências humanas e sociais que submetem suas propostas ao Comitê de Ética desconsiderariam a ética na relação com os participantes do estudo, apenas questionamos os motivos pelos quais existe a necessidade de que nossos trabalhos sejam "validados", "aprovados" por um comitê externo que não acompanha de perto a relação entre pesquisador-sujeitos tecida nos cotidianos da pesquisa de campo. Se a proposta de pesquisa precisa ser aprovada por um comitê externo, qual o lugar da ética na relação entre pesquisador e pesquisados? Se precisamos, a priori, de um comitê externo para "aprovar" eticamente a nossa proposta de pesquisa, quem "aprova" eticamente a nossa relação com os sujeitos?

Uma vez que privilegiamos a relação de dialogismo e alteridade com os sujeitos no Facebook, a postura ética é constituída durante todas as etapas da pesquisa; postura que, balizada na perspectiva bakhtiniana, não pode ser garantida pelos protocolos normativos externos à relação pesquisador-sujeitos. Dessa forma, "pensar o encontro como instaurador de uma ética, por sua vez, implica em abrir mão da pretensão da previsibilidade sobre o outro" (PEREIRA, 2015, p. 61), ainda mais considerando que a palavra é constantemente ativa e presente na passagem de boca em boca no processo comunicacional dialógico. (BAKHTIN, 2008). Nesse contexto, Pereira (2015, p. 56) novamente nos ajuda a compreender que se o compromisso ético 
do pesquisador com os sujeitos recai única e exclusivamente na preocupação pela assinatura do termo de consentimento, "perceberemos que é a norma que assume o lugar de poder na construção das relações de alteridade entre os sujeitos na dinâmica social, bem como na dinâmica de pesquisa”. Se é a norma que assume o lugar na relação eu-outro, de que ética estamos falando na relação entre pesquisador e seus tantos outros?

0 encontro de alteridades que se estabelece no grupo do Facebook nos fez conceber os jovens como sujeitos da experiência, caracterizados

[.....] por sua passividade, por sua receptividade, por sua disponibilidade, por sua abertura. Trata-se [...] de uma passividade feita de paixão, de padecimento, de paciência, de atenção, como uma receptividade primeira, como uma disponibilidade fundamental, como uma abertura essencial. (LARROSA, 2002, p. 24).

Essa receptividade consolida as relações entre os membros do grupo e torna cada integrante cúmplice de um aprender-ensinar com o outro sobre os desafios de se viver em diversos contextos sociais no qual impera a ótica heteronormativa. Isso condiz com as colocações de Oliver, quando afirma: "eu me interesso pelo assunto sim, aprendo cada vez mais com o grupo" e "Pode contar comigo e com o grupo pro que precisar”. Receptividade e disponibilidade são fundamentais na pesquisa que privilegia, com o outro, uma relação dialógica e alteritária dentro de uma dimensão de horizontalidade das vozes na produção do conhecimento. Como nos lembra Amorim (2009, p. 12, grifos da autora), “o objeto das ciências exatas, como todo objeto de discurso e de conhecimento é um objeto falado e o das ciências humanas, além de ser falado, é um objeto falante". Essa especificidade das ciências humanas nos apresenta a possibilidade de pesquisar com outros sujeitos, igualmente expressivos e falantes. (BAKHTIN, 2008).

Receptividade e disponibilidade para a escuta do outro também significa compreender que a participação dos sujeitos no estudo de campo não é obrigatória, mas voluntária. Nem todos os integrantes do grupo no Facebook têm o mesmo interesse em enriquecer as reflexões quando determinados assuntos são postados e comentados. Optando por um pseudônimo em homenagem ao nome do pesquisador (Dilton), o jovem Dalton, durante uma conversa que envolveu dezenas de postagens e curtidas no grupo, foi enfático ao dizer que "Se tiver mais do que 3 comentários eu 
não leio". Isso não quer dizer que Dalton não participe das conversas online, mas vêm optando por aquelas que demandam menos tempo para serem comentadas com os demais integrantes do grupo. Diante do exposto, perguntamos: como tornar as conversas no grupo instigantes o suficiente para que um número cada vez maior de participante poste e comente as contribuições dos outros membros? Caminhando nessa linha de pensamento, concordamos com Bakhtin (2011, p. 408, grifos do autor), para quem “pergunta e resposta não são relações (categorias) lógicas; não podem acabar em uma só consciência (una e fechada em si mesma); toda resposta gera uma nova pergunta". Como criar, na relação com os sujeitos, diálogos que busquem respostas e que suscitem novas perguntas na medida em que eu afeto e me afeto pelo outro? Com a perspectiva bakhtiniana aprendemos que, para além do desejo de meras respostas às nossas perguntas, almejamos a partilha de sentidos entre duas ou mais consciências que possibilitem fundar uma ética em que o meu modo de ser é (re)inventado na medida em que eu interajo com meus tantos outros.

\section{“Seria Melhor Você Criar Então um Grupo Secreto só Para Isso, Não?”: a Entrada em Campo}

A partir das contribuições bakhtinianas, compreendemos a necessidade da presença do outro como forma de promover a comunicação dialógica e, dessa forma, torna-se essencial a parceria e o envolvimento dos sujeitos no estudo de campo. Essa necessidade absoluta do outro é percebida nas palavras de Bakhtin (2011, p. 373), quando mostra que cada consciência se desperta com a consciência alheia, ao mesmo tempo em que cada olhar é provisoriamente preenchido pelo olhar do outro (e vice-versa): “Tudo o que me diz respeito, a começar pelo meu nome, chega ao mundo exterior à minha consciência pela boca dos outros”.

Para atender aos objetivos específicos de sua investigação, o pesquisador busca nas palavras dos sujeitos respostas às perguntas dele, ao mesmo tempo em que lança outras perguntas em resposta às palavras dos sujeitos. Esse movimento de perguntas-respostas requer a presença dos sujeitos envolvidos, que também participam da formulação de novas perguntas e respostas. Ao serem apresentados, no 
Facebook, à proposta do estudo de doutorado ${ }^{8}$, foi possível perceber uma relação de abertura e disponibilidade, corroborando com a ideia de que pesquisador e pesquisados constituem-se parceiros da tarefa de refletir coletivamente sobre possíveis caminhos teórico-metodológicos, conforme sugere a conversa online com Justgia:

Justgia: Oi Dilton. Acho muito legal a sua pesquisa e topo participar sim. Como seria a participação exatamente?

Dilton: Que ótimo, Justgia! A participação de vocês é fundamental.

Justgia: $O$ seu objetivo depende de uma amostragem grande de pessoas? Eu poderia ajudar vendo com outros amigos se você quiser.

Dilton: A participação vem sendo feita no próprio grupo.

Justgia: $A h$

Dilton: ah, ótimo! obrigado pela força e pela disponibilidade. Pois é, geralmente eu trabalho com poucas pessoas no estudo de campo.

Justgia: Seria melhor você criar então um grupo secreto só para isso, não?

Dilton: o grupo, por enquanto, é mais do que suficiente para fazer um belo trabalho! $O$ povo é muito animado e participativo.

Justgia: ah ta. Tranquilo então, vou dar uma olhada e qq coisa eu falo com você aqui de novo.

Dilton: Eu poderia criar um grupo para isso, mas se ele já existe e o pessoal é super animado, para que criar OUTRO? Claro, fica a vontade para perguntar o que você quiser.

Justgia: sim, lógico, eu pensei em criar outro se precisasse de mais pessoas, não tinha lido sua resposta ainda.

A parceria com os jovens os torna coautores e protagonistas de um trabalho que é aberto ao diálogo e que reflete constantemente sobre os aspectos teórico-metodológicos levantados pelos próprios sujeitos, conforme Justgia o faz nas seguintes colocações: “Como seria a participação exatamente?” e "Seria melhor você criar então um grupo secreto só para isso, não?’. Assumir o dialogismo e a alteridade à luz das contribuições bakhtinianas é reconhecer "o sujeito da pesquisa [...] como alguém cuja palavra se confronta com a do pesquisador, refratando-a e exigindo-lhe resposta”. (PEREIRA; SALGADO; JOBIM E SOUZA, 2009, p. 1023). Assim, pesquisador

\footnotetext{
${ }^{8}$ Conforme mencionado na introdução, o trabalho de doutorado teve como proposta investigar as experiências sociais que marcam negativamente jovens não-heterossexuais, constantemente colocados na posição de pessoas que são recusadas com repugnância.
} 
e sujeitos colocam-se à disposição do outro para buscar respostas (sempre provisórias) ainda não fornecidas. As perguntas de Justgia são significativas porque revelam a implicação e o envolvimento dela com o estudo que vem sendo desenvolvido com os membros do grupo no Facebook. Diante das colocações dela, outras reflexões podem ser levantadas: quais os critérios utilizados pelo pesquisador para escolher seu(s) campo(s) empírico(s) na internet? Quais as possibilidades de interação proporcionadas pela pesquisa online? Criar um espaço na internet para fins de pesquisa ou utilizar os espaços já constituídos pelos grupos de sujeitos? E como apresentar a proposta de pesquisa para os jovens internautas?

Caminhamos na mesma linha de pensamento de Hine (2009), para quem as reflexões de pesquisa na internet não apresentam como premissa responder prontamente aos desafios metodológicos enfrentados durante seu desenvolvimento, mas reconhecer a necessidade de formular estratégias que sejam importantes e significativos na condução do trabalho de campo. Dessa forma, não é nossa intenção aqui concordar que haveria uma escolha metodológica "melhor", mas compreender que as reflexões teórico-metodológicas perpassam todas as etapas da pesquisa, inclusive quando o texto escrito é finalizado.

\section{“Fico Ansioso pra Ler Seu Trabalho”: o Retorno do Texto Escrito aos Sujeitos da Pesquisa}

Macedo e Flores (2012) dedicaram-se a refletir sobre uma das etapas da pesquisa que ainda é pouco explorada: o retorno do texto escrito aos sujeitos e às instituições parceiras que cederam o espaço para a realização da investigação. De acordo com elas,

Compartilhamos a ideia de que o texto de pesquisa morre como escrita, mas renasce na ação dos leitores que passam a the conferir novos sentidos e significados. Uma pesquisa científica ganha vida não só nas diferentes leituras e discussões que motiva, mas, sobretudo, nas questões que suscita mesmo quando supostamente termina, reforçando a noção de inacabamento que perpassa toda a condição humana (MACEDO; FLORES, p. 244). 
As autoras vão além da mera "entrega do produto escrito", materializado na forma das "dissertações" e "teses", e problematizam questões para o campo de estudos das crianças e das infâncias, reconhecendo a necessidade de rever as diferentes possibilidades de apresentação dos textos escritos pelos adultos a fim de que produzissem novos sentidos para as crianças. Para isso, elas se inspiram no trabalho de Amorim (2001), que também se preocupou sobre a questão do retorno da pesquisa por meio da visita dela a uma comunidade do Rio de Janeiro adotada como campo empírico. Macedo e Flores (2012, p. 247) perceberam a necessidade de um olhar mais atento sobre as implicações teórico-metodológicas que envolvem a criança e a escrita do texto e lançam a seguinte pergunta: “Como o pesquisador constrói o que quer contar?”. Se o pesquisador constrói o que quer contar, o que ele deixa de contar e por quê? E a quem se destina o texto escrito de uma pesquisa?

A partir de algumas conversas estabelecidas com os jovens no Facebook, já era possível perceber no início do segundo semestre de 20140 interesse pela leitura do texto escrito da tese, finalizado somente no primeiro trimestre de 2017:

1

Ian McKellen: mto sucesso pra vc rapaz mto linda essa sua área de pesquisa fico ansioso pra ler seu trabalho Dilton: Obrigado pela força, Ian McKellen! sucesso para todos nós. 2

Paulo: Oi Dilton! CLARO que pode [contar comigo]! Seja bem vindo [no grupo]. Inclusive saber como vc está trabalhando isso é muito positivo pra mim, que serei um futuro professor e não faço a mínima como trabalhar esse tema (que é difícil!) na escola. Então qualquer pergunta que tiver pra fazer e no que eu puder ajudar, por favor, sinta-se a vontade. Quando tiver a tese pronta e os resultados compartilha com a gente!

Dilton: Olá Paulo! Fico feliz que esteja animado com o tema e querendo saber melhor das minhas questões de pesquisa. Assim que os trabalhos forem sendo finalizados/publicados, pode deixar que eu compartilho com vocês. Ainda está tudo muito recente, a pesquisa começou ano passado [2013] e ainda tenho muitos anos pela frente para finalizá-la. E tenha certeza de que o tema é bem provocante e instigante $e$ as questões levantadas por vocês no grupo são igualmente desafiantes para mim, que já sou professor.

3

Dilton: [...] Seria excelente contar com você! E pode perguntar a vontade tudo o que precisar sobre a pesquisa 
Mafalda: A pergunta é: por que não [participar]? Topo sim! Inclusive me ajudaria a pensar sobre isso - uma vez que muitas vezes percebo mais a ação dos outros e negligencio as minhas. [...] Você me lembrou que nas últimas discussões de um outro grupo aqui no Facebook. [...] a gente estava pensando o quão seria engrandecedor ter essas questões debatidas para a licenciatura. Beijo grande!

Novamente buscamos inspiração em Macedo e Flores (2012) para tecermos as seguintes questões teórico-metodológicas sobre o retorno do texto escrito aos sujeitos. Diferentemente do contexto das infâncias, os jovens que integraram a recém-finalizada pesquisa de doutorado são jovens internautas estudantes das ciências biológicas de uma universidade pública do Rio de Janeiro. Dessa forma, como apresentar aos jovens da pesquisa o texto que foi escrito com a participação deles? 0 que eles terão a dizer sobre isso? Como fazer com que os sujeitos se reconheçam no texto escrito pelo pesquisador? Qual a relação de alteridade e dialogismo que será criada quando o texto for, finalmente, apresentado e lido pelos sujeitos? Quais contribuições teórico-metodológicas poderão emergir quando estes jovens “reencontrarem-se” no texto escrito? E será que o farão?

A partir dos relatos de lan McKellen "fico ansioso pra ler seu trabalho" e Paulo “Quando tiver a tese pronta e os resultados compartilha com a gente?", é nítida a curiosidade promovida no Facebook pelo encontro proporcionado entre pesquisador e sujeitos. Essa curiosidade também diz respeito à forma como a escrita do texto convidará as vozes dos sujeitos a enredarem-se à luz da fundamentação teórica adotada. Além disso, cabe ressaltar que Paulo "serei um futuro professor e não faço a mínima como trabalhar esse tema (que é difícil!) na escola” e Mafalda “a gente estava pensando o quão seria engrandecedor ter essas questões debatidas para a licenciatura" revelam também a preocupação em conhecer melhor as questões de gênero e sexualidade que foram discutidas com o grupo no Facebook. Além das importantes conversas online estabelecidas previamente à finalização da pesquisa, a tese certamente suscitará outros momentos de reflexão que poderão nortear os jovens, estudantes da licenciatura, no trabalho em sala de aula com o tema "gênero e sexualidade". Ao colocar em prática a comunicação dialógica e adotar uma postura de alteridade, a produção de conhecimento com os sujeitos no trabalho de campo não deixa dúvidas de que seria “impossível escapar intacto e imune às alterações que as 
palavras e os atos do outro provocam. Conceitos, valores e pontos de vista, advindos de lugares sociais [...] diferentes, transformam-se mutuamente". (JOBIM E SOUZA; SALGADO, 2008, p. 497).

Os dizeres de Ian McKellen, Paulo e Mafalda nos remetem à ideia de que o texto escrito é um novo encontro entre o pesquisador e sujeitos, pois ele é necessário para dar forma e conteúdo aos acontecimentos ocorridos no campo da pesquisa: "e é neste momento que o texto escrito entra em cena. A escrita do pesquisador consolida a criação de conceitos cuja pretensão é criar zonas provisoriamente estáveis de pensamento sobre uma dada realidade”. (JOBIM E SOUZA; ALBUQUERQUE, 2012, p. 116). Nesta perspectiva, reconhecendo a coautoria e a implicação dos sujeitos com a pesquisa, também não há como desconsiderar a provisoriedade das reflexões do texto escrito, uma vez que cada sujeito-leitor atribuirá sentidos diversos sobre as reflexões tecidas e que são assinadas pelo pesquisador-autor.

\section{“Quem Não Comenta, Mas ‘Curte’, Também Participa?”: Sobre Visualizações e “Curtidas"}

Pesquisar com outros internautas implica na promoção da interação e do diálogo a partir de imagens, vídeos e sons que se misturam e, dessa forma, produzem dinâmicas ciberculturais que ampliam os processos comunicacionais entre os sujeitos. Considerando as possibilidades engendradas pela escrita mediada pelo computador e pelos diferentes tipos de arquivos com os quais interagimos na internet, quais os desafios de fazer pesquisa a partir da promoção do estabelecimento da comunicação na/em rede? Como descrever, a partir de um texto escrito, as experiências vivenciadas com os sujeitos na internet? Em outras palavras, como seria possível explorar e analisar as dinâmicas ciberculturais se a escrita de um texto é realizada linearmente, da esquerda para a direita e de cima para baixo? Sobre isso, Ferreira (2014, p. 47-48) revela que:

[...] o desafio de trazer para o texto a riqueza das experiências é enorme. Como traduzir em palavras os risos, os olhares, a confusão e algazarra dos passeios, as reticências dos desconfiados, a cumplicidade, as trocas de mensagens, as 'curtidas' e as indiferenças? Cada postagem, cada mensagem, cada imagem produzida, merece um olhar atento e sensível. A escrita é o momento de recriar e trazer as 
diversas vozes que constituem o ato da pesquisa e que estiveram presentes todo o tempo - jovens, professores, toda a equipe de atores da escola, autores que me acompanham, colegas do grupo de pesquisa, orientadora, pessoas com as quais conversei e a minha própria voz.

As reflexões de Ferreira (2014) acima ressaltam os desafios encontrados pela pesquisadora em sua investigação de doutorado. Ela adotou o Facebook como espaço de comunicação com os sujeitos (alunos e professores), ao mesmo tempo em que também realizou oficinas presenciais com jovens em uma escola pública do Rio de Janeiro. Um dos elementos apresentados por ela, pouco explorado pelas pesquisas online, são as populares "curtidas” presentes na rede social Facebook. Afinal, nos perguntamos: “quem não comenta, mas 'curte', também participa?’.

Concordamos com Ferreira (2014, p. 114), para quem “o clique no ícone não se configura como escrita, mas a curtida fala muito para aqueles que se apropriam desse código". Ela reitera que a "curtida" funcionaria para "validar" um pensamento e corroborar com o que vem sendo discutido entre os internautas num determinado momento. Considerando que a presença de cada integrante de nossa "lista de amigos" do Facebook altera as dinâmicas comunicacionais de nossa rede, por que desconsiderar o ato de "curtir" como não constituinte da relação com o outro na internet? Qual o sentido de produzir e compartilhar um texto se ninguém o visualizará e/ou o "curtirá"? 0 que queremos ressaltar é a necessidade que sentimos do outro para visualizar e "validar" o que produzimos e compartilhamos na rede. Nesse contexto, o que torna uma postagem digna de ser "curtida"? E o que impede que uma postagem seja "curtida"?

As sociabilidades que emergem no contexto das dinâmicas das redes sociais digitais revelam a necessidade dos internautas de permanecerem interconectados, (co)criando saberes na medida em que dialogam cotidianamente. (BONILLA, 2009). A criação de vínculos afetivos e o desejo pelo diálogo na/em rede ocorrem pelo "simples fato de que é bom estar junto, ainda mais quando o compartilhamento, a reciprocidade e a cumplicidade não têm outro destino ou finalidade a não ser o puro, singelo e radical prazer de estar junto". (SANTAELLA; LEMOS, 2010, p. 25-26). Na ótica bakhtiniana, o estar junto permite que pesquisador e sujeitos tenham uma oportunidade única para, uns com os outros, aprenderem, refletirem, completarem-se, 
transformarem-se, e resinificarem-se durante o transcorrer de todo o processo investigativo. (FREITAS, 2009). Dessa forma, a visualização e a "curtida" também se constituem para "validar" a forma como pensamos, nos colocamos no mundo e estamos implicados na relação com o outro na internet; uma relação não necessariamente de concordância, mas de possibilidades dialógicas que o encontro com o outro proporciona.

\section{Breves Palavras Finais}

À luz das contribuições bakhtinianas, a pesquisa é um acontecimento. Não se busca uma verdade, válida para todo e qualquer contexto. É na relação livre, espontânea e irrepetível com o outro que o percurso de pesquisa possibilita produzir enunciados não necessariamente harmônicos, mas que colocam em tensão ideias partilhadas por sujeitos que são instigados pelo desejo de conhecer e se deixar conhecer. 0 diálogo “é muito mais uma arena” (AMORIM, 2008, p. 107) que envolve o compartilhamento de ideias nem sempre convergentes. Os sentidos produzidos pela relação entre os sujeitos revelam que há formas distintas de perceber e interpretar os acontecimentos da vida. 0 diálogo com o outro é capaz de abalar as nossas certezas, que dão lugar às tantas incertezas que somente outro olhar, diferente, é capaz de proporcionar. Não nos interessou aqui investigar a linguagem sob a ótica da linguística, mas a linguagem pelo viés da comunicação dialógica que, segundo Bakhtin (2008, p. 209, grifo do autor), “constitui o verdadeiro campo da vida da linguagem". Ao mesmo tempo em que se constitui como um processo permanente de negociação, a linguagem é o convite para que os sujeitos criem formas de interagir cotidianamente.

Os jovens da pesquisa encontram no Facebook um lugar para estarem ainda mais próximos, intercambiando e discutindo ideias. É dentro desta perspectiva que o trabalho de pesquisa se situa, buscando apresentar o que cada um pensa e repensa no embate das diferentes ideias. Para Bakhtin (2011, p. 394-395), “a penetração no outro (fusão com ele) e a manutenção da distância (do meu lugar), manutenção que assegura o excedente de conhecimento", são alguns dos aspectos que constituem a relação dialógica eu-outro. Do lugar que o pesquisador ocupa, ele entra em contato e 
reconhece a existência de outro sujeito, igualmente expressivo e falante, que partilha sentidos e auxilia na compreensão de uma determinada realidade.

Ao refletirmos nesse texto sobre questões teórico-metodológicas, com ênfase em aspectos como autorização, ética, participação dos sujeitos na investigação, a entrada em campo e o retorno do texto escrito aos sujeitos, tivemos a oportunidade de perceber que a comunicação dialógica, aliada a uma postura ética e de alteridade, nos permite evidenciar o aspecto de coautoria dos sujeitos no trabalho. Isso porque é através de práticas dialógicas que o pesquisador é instigado a falar e a ouvir o outro e, dessa forma, refletir sobre os percursos teórico-metodológicos na medida em que o trabalho de campo é desenvolvido em parceria. Reconhecer o sujeito como participante da pesquisa é legitimar a necessidade absoluta do outro na produção de conhecimento, privilegiando o encontro de diversos pontos de vista que auxilia o pesquisador na percepção de outras formas de interpretar o mundo.

\section{Referências}

AMORIM, M. Memória do objeto: uma transposição bakhtiniana e algumas questões para a educação. Bakhtiniana, São Paulo, v. 1, n. 1, p. 8-22, 2009. Disponível em: https://bit.ly/2RDnfze. Acesso em: 1 ago. 2017.

AMORIM, M. O pesquisador e seu outro: Bakhtin nas ciências humanas. São Paulo: Musa Editora, 2001.

AMORIM, M. Cronotopo e exotopia. In: BRAIT, B. (org.). Bakhtin: outros conceitos-chave. São Paulo: Contexto, 2008. p. 95-114.

BAKHTIN, M. Estética da criação verbal. Tradução de Paulo Bezerra. 6. ed. São Paulo: Martins Fontes, 2011.

BAKHTIN, M. Problemas da poética de Dostoiévski. Tradução de Paulo Bezerra. 4. ed. Rio de Janeiro: Forense Universitária, 2008.

BONILLA, M. H. S. Escola aprendente: comunidade em fluxo. In: FREITAS, M. T. A. (org.). Cibercultura e formação de professores. Belo Horizonte: Autêntica, 2009. p. 23-40.

COUTO JUNIOR, D. R.; FERREIRA, H. M. C.; OSWALD, M. L. M. B. Compartilhando experiências sobre o "armário": as conversas online como procedimento metodológico da pesquisa histórico-cultural na cibercultura. Revista Interface Científica Educação, Aracaju, v. 6, n. 1, p. 23-34, out. 2017. Disponível em: https://bit.ly/2SNjulP. Acesso em: 3 abr. 2018.

FERREIRA, H. M. C. Dinâmicas de uma juventude conectada: a mediação dos dispositivos móveis nos processos de aprender-ensinar. 2014. 272f. Tese (Doutorado 
em Educação) - Faculdade de Educação, Universidade do Estado do Rio de Janeiro, Rio de Janeiro, 2014.

FREITAS, M. T. A. A perspectiva sócio-histórica: uma visão humana da construção do conhecimento. In: FREITAS, M. T. A.; JOBIM E SOUZA, S.; KRAMER, S. (org.). Ciências humanas e pesquisa: leituras de Mikhail Bakhtin. 2. ed. São Paulo: Cortez, 2007. p. 26-38.

FREITAS, M. T. A. A pesquisa de abordagem histórico-cultural: um espaço educativo de constituição de sujeitos. Revista Teias, Rio de Janeiro, v. 10, n. 19, p. 1-12, 2009.

Disponível em: https://bit.ly/2yTgpPc. Acesso em: 10 abr. 2017.

GERALDI, J. W. A diferença identifica: a desigualdade deforma: percursos bakhtinianos de construção ética e estética. In: FREITAS, M. T. A.; JOBIM E SOUZA, S.; KRAMER, S. (org.). Ciências humanas e pesquisa: leituras de Mikhail Bakhtin. 2. ed. São Paulo: Cortez, 2007. p. 39-56.

HINE, C. Virtual ethnography: modes, varieties, affordances. In: FIELDING, N.; LEE, R. M.; BLANK, G. (org.). The SAGE handbook of online research methods. Los Angeles: Sage, 2008. p. 257-270.

HINE, C. How can qualitative internet researchers define the boundaries of their projects? In: MARKHAM, A. N.; BAYM, N. (org.). Internet inquiry: conversations about method. Los Angeles: Sage, 2009. p. 1-20.

JOBIM E SOUZA, S.; ALBUQUERQUE, E. D. P. A pesquisa em ciências humanas: uma leitura bakhtiniana. Bakhtiniana, São Paulo, v. 7, n. 2, p. 109-122, jul./dez. 2012. Disponível em: https://bit.ly/2qu49A5. Acesso em: 15 set. 2015.

JOBIM E SOUZA, S.; SALGADO, R. G. Mikhail Bakhtin e a ética das imagens nos estudos da infância: uma proposta de pesquisa-intervenção. In: CASTRO, L. R.; BESSET, V. L. (org.). Pesquisa-intervenção na infância e juventude. Rio de Janeiro: Trarepa: FAPERJ, 2008. p. 490-513.

KRAMER, S. Autoria e autorização: questões éticas na pesquisa com crianças. Cadernos de Pesquisa, São Paulo, n. 116, p. 41-59, jul. 2002. Disponível em: https://bit.ly/2Do3jgz. Acesso em: 15 abr. 2016.

LARROSA, J. Notas sobre a experiência e o saber de experiência. Revista Brasileira de Educação, Rio de janeiro, n. 19, p. 20-28, jan./fev./mar./abr. 2002. Disponível em: https://bit.ly/1ryFC8Q. Acesso em: 10 mar. 2017.

LEMOS, A. Cibercultura como território recombinante. In: MARTINS, C. D.; CASTRO E SILVA, D.; MOTTA, R. (org.). Territórios recombinantes: arte e tecnologias. São Paulo: Instituto Sérgio Motta, 2007. p. 35-48.

MACEDO, N. M. R. “Você tem face?” Sobre crianças e redes sociais online. 2014. 296f. Tese (Doutorado em Educação) - Faculdade de Educação, Universidade do Estado do Rio de Janeiro, Rio de Janeiro, 2014.

MACEDO, N. M. R.; FLORES, R. L. B. 0 retorno às crianças como etapa da pesquisa feita com elas: caminhos e desafios. In: PEREIRA, R. M. R.; MACEDO, N. M. R. (org.). Infância em pesquisa. Rio de Janeiro: Nau, 2012. p. 237-257. 
NICOLACI-DA-COSTA, A. M. Revoluções tecnológicas e transformações subjetivas. Psicologia: Teoria e Pesquisa, Brasília, v. 18, n. 2, p. 193-202, maio/ago. 2002. Disponível em: https://bit.ly/2je2DPf. Acesso em: 10 jun. 2017.

NUNES, M. F. R.; KRAMER, S. Linguagem e alfabetização: dialogando com Paulo Freire e Mikhail Bakhtin. Revista Contemporânea de Educação, Rio de Janeiro, v. 6, n. 11, p. 26-47, jan./jul. 2011. Disponível em: https://bit.ly/20qqTdR. Acesso em: 10 abr. 2017.

PEREIRA, R. M. R. Por uma ética da responsividade: exposição de princípios para a pesquisa com crianças. Currículo Sem Fronteiras, [S. l.] v. 15, n. 1, p. 50-64, jan./abr. 2015. Disponível em: https://bit.ly/2QIFs3Z. Acesso em: 23 maio 2017.

PEREIRA, M. R. R.; SALGADO, R. G.; JOBIM E SOUZA, S. Pesquisador e criança: dialogismo e alteridade na produção da infância contemporânea. Cadernos de Pesquisa, São Paulo, v. 39, n. 138, p. 1019-1035, set./dez. 2009. Disponível em: https://bit.ly/2D4x595. Acesso em: 5 mar. 2015.

PRETTO, N. L. Redes sociais e educação: o que quer a geração alt+tab nas ruas? Liinc em Revista, Rio de Janeiro, v. 10, n. 1, p. 344-350, maio 2014. Disponível em: https://bit.ly/2zuoeKF. Acesso em: 15 jan. 2017.

RAMOS, B. S.; SCHAPPER, I. (Des)atando os nós da pesquisa na abordagem histórico-cultural. In: FREITAS, M. T. A.; RAMOS, B. S. (org.). Fazer pesquisa na abordagem histórico-cultural: metodologias em construção. Juiz de Fora: Ed. UFJF, 2010. p. 25-35.

RECUERO, R. Atos de ameaça à face e à conversação em redes sociais da internet. In: PRIMO, A. (org.). Interações em rede. Porto Alegre: Editora Sulina, 2013. p. 51-69.

ROSA, A. C. P. S.; FERREIRA, H. M. C.; OSWALD, M. L. M. B. Práticas culturais juvenis: máscaras contemporâneas. Revista da FAEEBA, Salvador, v. 19, n. 33, p. 215-227, jan./jun. 2010. Disponível em: https://bit.ly/2PFeAid. Acesso em: 25 maio. 2012.

SANTAELLA, L. Intersubjetividade nas redes digitais: repercussões na educação. In: PRIMO, A. (org.). Interações em rede. Porto Alegre: Editora Sulina, 2013. p. 33-47.

SANTAELLA, L.; LEMOS, R. Redes sociais digitais: a cognição conectiva do Twitter. São Paulo: Paulus, 2010. 